\title{
Correct usage, ease of use, and preference of two dry powder inhalers in patients with COPD: analysis of five phase III, randomized trials
}

This article was published in the following Dove Press journal: International Journal of COPD

16 August 2016

Number of times this article has been viewed

\author{
John H Riley' \\ Maggie Tabberer ${ }^{2}$ \\ Nathalie Richard ${ }^{3}$ \\ Alison Donald ${ }^{3}$ \\ Alison Church ${ }^{3}$ \\ Stephanie S Harris ${ }^{3}$ \\ 'MDC Global Clinical Development - \\ UK, GlaxoSmithKline, ${ }^{2}$ Value Evidence \\ and Outcomes, GlaxoSmithKline, \\ Uxbridge, Middlesex, UK; ${ }^{3}$ Respiratory \\ Medicines Development Center, \\ GlaxoSmithKline, Durham, NC, USA
}

Correspondence: John H Riley MDC Global Clinical Development - UK, GlaxoSmithKline, Stockley Park West, I-3 Iron Bridge Road, Uxbridge, Middlesex, UBII IBS, UK

Tel +4420899024l8

Email john.h.riley@gsk.com
Background: Handheld inhalers are used to deliver treatment for COPD. Incorrect usage leads to suboptimal disease control. Complex treatment regimens and use of multiple inhalers may reduce patient compliance. The Anoro Ellipta ${ }^{\mathrm{TM}}$ dry powder inhaler (DPI) simultaneously delivers umeclidinium bromide (UMEC) and vilanterol (VI) without coformulation being required.

Aim: To assess the correct usage and ease of use of the Ellipta ${ }^{\mathrm{TM}}$ DPI administering UMEC/VI

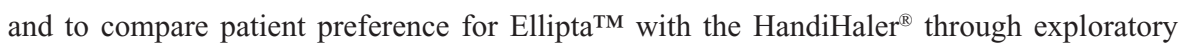
analyses of patient and observer questionnaires in five Phase III studies.

Methods: Two Phase III, 3-month double-blind, placebo-controlled studies assessed the correct usage of the Ellipta ${ }^{\mathrm{TM}}$ DPI at Day 1 and after 6 weeks, and ease of use of the Ellipta ${ }^{\mathrm{TM}}$ DPI using a nonvalidated patient questionnaire after 6 weeks or early withdrawal. In three 6-month, blinded double-dummy, active comparator studies (two Phase IIIa and one Phase IIIb), patients completed a COPD device preference questionnaire between the Ellipta ${ }^{\mathrm{TM}}$ DPI and the HandiHaler $^{\circledR}$ at Day 168 (Week 24) or early withdrawal.

Results: In the 3-month placebo-controlled studies, $\geq 98 \%$ of patients used the Ellipta ${ }^{\mathrm{TM}}$ DPI correctly and $99 \%$ of patients found the inhaler easy/very easy-to-use and the dose counter easy/ very easy to read. Across the two Phase IIIa active comparator studies, patients consistently stated a preference for the Ellipta ${ }^{\mathrm{TM}}$ DPI over HandiHaler ${ }^{\circledR}$ regarding the number of steps to use $(59 \%$ vs $17 \%)$, time taken to use ( $62 \%$ vs $14 \%)$, and ease of use (63\% vs $15 \%)$ regardless of which inhaler contained active drug. Results were consistent in the Phase IIIb active comparator study.

Conclusion: Delivery of UMEC/VI via the Ellipta ${ }^{\mathrm{TM}}$ DPI was considered easy-to-use, and patients with COPD demonstrated clear preference for this inhaler compared with HandiHaler ${ }^{\mathbb{B}}$.

Keywords: ease of use, Ellipta ${ }^{\mathrm{TM}}$, inhaler, preference, chronic obstructive pulmonary disease (COPD), umeclidinium/vilanterol

\section{Introduction}

Chronic obstructive pulmonary disease (COPD) is a significant cause of morbidity and mortality, and its prevalence is predicted to rise with an aging population. ${ }^{1}$ Handheld inhalers are often used to treat COPD and deliver drug directly into the airways. Targeted delivery achieves higher concentrations at the site of action while minimizing the risks of systemic side effects. ${ }^{2,3}$

Data suggest that $50 \%-80 \%$ of patients are not using their inhaler correctly, possibly leading to suboptimal disease control, increased risk of exacerbations and 
hospitalization, and rising health care costs. ${ }^{3}$ Furthermore, therapeutic management of COPD often involves the use of multiple inhalers, and this increased complexity in treatment regimen decreases medication compliance, increasing the risk of poor disease management. ${ }^{3}$ In order to maximize adherence and treat COPD effectively, patient acceptance and ability to use their inhalers is a major factor. ${ }^{4}$ In developing new treatments for COPD, assessment of ease of use and patient preference for any new inhaler is important. ${ }^{5}$

Coformulation of treatments, to allow simultaneous delivery, reduces the number of inhalers required, simplifies treatment, and has been employed to address adherence issues. ${ }^{6}$ However, coformulation can be challenging with the potential for physicochemical interactions between drug entities. ${ }^{7}$ The Ellipta ${ }^{\mathrm{TM}}$ dry powder inhaler (DPI) contains two blister strips from which inhalation powders are delivered, enabling simultaneous delivery of two compounds without the need for coformulation. The Ellipta ${ }^{\mathrm{TM}}$ DPI inhaler design incorporated patient input in order to optimize patient handling and ease of use, with an overall aim of increasing patient compliance. ${ }^{8}$ This inhaler has been used in a series of clinical studies to deliver dual therapy of fluticasone furoate (FF)/vilanterol (VI) to patients with asthma (HZA106827; NCT01165138), ${ }^{9}$ and COPD ${ }^{10-13}$ and umeclidinium bromide (UMEC) and VI dual therapy or component monotherapies to patients with COPD. ${ }^{14-18}$ High patient satisfaction was reported following FF/VI delivery via the Ellipta ${ }^{\mathrm{TM}}$ DPI in asthma and COPD, with both patient populations indicating a preference over their currently prescribed inhaler. ${ }^{19}$

This article describes the exploratory outcomes of the use of the Ellipta ${ }^{\mathrm{TM}}$ DPI during two 3-month double-blind, placebo-controlled Phase III trials of UMEC/VI, UMEC, VI, or placebo (all delivered by the ElliptaTM DPI). In these studies, correct usage and ease of use of the ElliptaTM DPI were assessed. ${ }^{20}$ Data from three 6-month double-dummy, active comparator trials (two Phase IIIa and one Phase IIIb trials) including UMEC/VI, UMEC, or VI (all delivered via the Ellipta ${ }^{\mathrm{TM}}$ DPI) and tiotropium (TIO; delivered by HandiHaler $^{\circledR}$ ) are also reported. In these studies, COPD patient preference for the Ellipta ${ }^{\mathrm{TM}}$ DPI or HandiHaler ${ }^{\circledR}$ was assessed. ${ }^{17,21}$

\section{Methods Study designs}

In all the five studies, treatment compliance with the Ellipta ${ }^{\mathrm{TM}}$ DPI was monitored using the inhaler dose counter. In the three active comparator studies, treatment compliance with the HandiHaler ${ }^{\circledR}$ was assessed by counting capsules returned.
The study protocol and written informed consent form were reviewed and approved by the Chesapeake Institutional Review Board, as well as each relevant national, regional, or independent ethics committee or institutional review board, in accordance with Good Clinical Practice and the principles of the Declaration of Helsinki, with written informed consent obtained from all patients.

\section{Three-month placebo-controlled studies}

Two 3-month Phase III, placebo-controlled studies (DB2114417 [NCT01328444] and DB2114418 [NCT 01323660]) with a double-blind, incomplete block, two-period crossover design assessed once-daily (QD) UMEC/VI (125/25 mcg and 62.5/25 mcg), UMEC (125 mcg and $62.5 \mathrm{mcg}$ ), VI $25 \mathrm{mcg}$, and placebo; all delivered in patients with COPD, using the Ellipta ${ }^{\mathrm{TM}} \mathrm{DPI} .{ }^{20}$ Questionnaires assessing ease of use and ease of determination of the number of doses left in Ellipta ${ }^{\mathrm{TM}}$ DPI (Figure 1) were administered during the first study treatment period (at Day 43). Correct usage of the DPI was demonstrated/assessed through Visits 4-6 (at Days 1, 2, and 43) by staff at the study site.

\section{Active comparator studies}

Inhaler preference was assessed using the COPD Device Preference Questionnaire (CDPQ; as described in the "Assessments" section) at Day 168 (Week 24) or the early withdrawal visit of two 6-month, Phase IIIa, blinded, double-dummy, parallel-group, active comparator studies (DB2113360 [NCT01316900] and DB2113374 [NCT01316913]) of UMEC/VI (125/25 and 62.5/25 mcg), UMEC $62.5 \mathrm{mcg}$, UMEC $125 \mathrm{mcg}$, and VI $25 \mathrm{mcg}$, administered QD, via the Ellipta ${ }^{\mathrm{TM}}$ DPI and TIO $(18 \mathrm{mcg})$ administered QD via the HandiHaler ${ }^{\circledR}$, in patients with COPD. ${ }^{17,21}$ During the studies, each patient used both inhalers daily, with one containing active treatment and the other placebo, depending on randomization. Since all the patients were using both inhalers throughout, it was possible to measure preference. The blinding process in these studies is described in the Supplementary materials; this did not affect the attributes

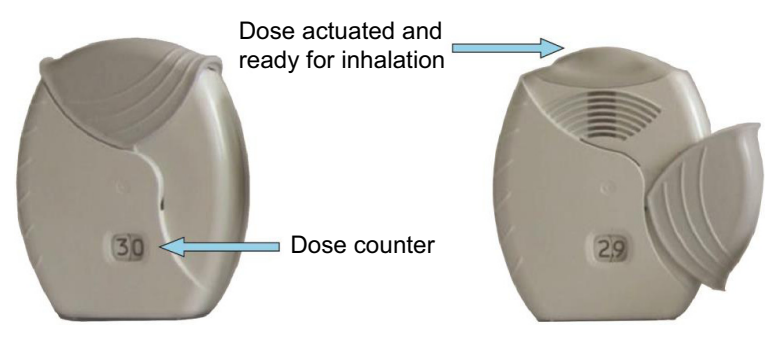

Figure I Illustration of the Ellipta ${ }^{\mathrm{TM}}$ dry powder inhaler. 
tested by the CDPQ, although one question was removed as a result of the blinding process. The CDPQ was also used at Day 168 or early withdraw visit to assess inhaler preference in an additional 6-month, Phase IIIb, blinded, doubledummy, parallel-group, active comparator study (ZEP117115 [NCT01777334]) of UMEC/VI 62.5/25 mcg delivered QD via the Ellipta ${ }^{\mathrm{TM}}$ DPI and TIO $18 \mathrm{mcg}$ delivered QD via the HandiHaler $^{\circledR}{ }^{21}$

\section{Assessments \\ Ellipta $^{\mathrm{TM}}$ DPI use and ease of use assessments (3-month placebo-controlled studies)}

Correct DPI usage and ease of use were assessed in the first treatment period of these crossover studies. At randomization (Day 1) and Day 2, patients were trained in the correct use of the Ellipta ${ }^{\mathrm{TM}}$ DPI using the instructions provided in the patient information leaflet. Placebo inhalers were used for demonstration purposes in the training. Correct use of the Ellipta $^{\mathrm{TM}}$ DPI involved three steps: 1) open the inhaler; 2) inhale the dose; and 3 ) close the inhaler.

Following a demonstration of correct use by study staff, the patient's competence was assessed using a placebo inhaler. If the patient did not use the inhaler correctly, further instructions were given before assessing patient competence again. The inhaler demonstration was repeated up to three times on both the occasions until the patient could use the inhaler correctly. Patients who were not able to use the inhaler correctly after three demonstrations at randomization were ineligible to enter the study. Correct inhaler use was reassessed at Day 43 (after 6 weeks of treatment) using the demonstration inhaler, without further verbal instruction or demonstration. If the patient did not perform the maneuvers correctly at the 6-week visit, the procedure was demonstrated once again. At each assessment visit, the number of times the patient required additional instruction was recorded. The person providing training and assessing correct use of the inhaler was the same individual, where possible, for each patient. After 6 weeks of treatment, patients were asked to rate the ease of use of the inhaler by answering two questions: 1) How do you rate the ease of use of the inhaler? 2) How easily are you able to tell how many doses of medication are left in the inhaler? For each of the questions, answers were recorded using a 5-point difficulty scale: 1) very easy, 2) easy, 3) neutral, 4) difficult, and 5) very difficult.

\section{CDPQ development}

Prior to the active comparator studies, the CDPQ was developed and validated by RTI Health Solutions in collaboration with GlaxoSmithKline. ${ }^{22}$ Although it was not formally assessed or validated in any of the three active comparator phase III studies described, the CDPQ was used as a tool in these studies to assess inhaler preference among patients. A pool of potential questions for inclusion in the CDPQ was developed from market research with patients with COPD currently using inhaled therapy and with physician experts currently prescribing inhalers. Questions were based on the important characteristics of COPD inhalers identified by patients and physicians. Having recognized that "ease of use" was an important feature, a question format for the draft item set of the CDPQ was developed to assess inhaler preference based on this aspect. Questions relating to specific aspects of "ease of use" that could be affected by the overlabeling used in the blinding process were not included in the draft CDPQ. To refine and assess content validity, the draft CDPQ was then tested in 16 iterative cognitive interviews with adult patients with COPD. ${ }^{22}$ To assist understanding, patients were able to handle a placebo Ellipta ${ }^{\mathrm{TM}}$ DPI inhaler during the interviews, and all recruited patients were already being treated with, and hence were familiar with, the HandiHaler ${ }^{\circledR}$. Participants in the first round of interviews $(n=8)$ provided feedback on their preferred phrasing of the draft CDPQ. The CDPQ was then modified based on these responses, and a second round of interviews $(n=8)$ was conducted during which participants assessed the modified CDPQ and provided additional input to confirm the content validity of the final version (shown in the Supplementary materials). ${ }^{22}$ The results of these interviews supported the content validity of the CDPQ, providing evidence that the measure adequately and appropriately assessed COPD DPI inhaler preference related to the most important ease of use concepts from the patient perspective. The second round of interviews also confirmed that the final wording of the instructions, the items, and their questionnaire responses were well understood by the patients with COPD providing evidence that the questionnaire adequately and appropriately assessed COPD DPI inhaler preference relating to ease of use. ${ }^{22}$

\section{Inhaler preference using the CDPQ (active comparator studies)}

The CDPQ was used on Day 168 (Week 24) or early withdrawal visit to assess inhaler preference in the three active comparator studies and consisted of three items that asked patients about their inhaler preference in terms of "number of steps," "time needed," and "ease of use." Choices of response included: preference for the Ellipta ${ }^{\mathrm{TM}}$ DPI, preference for HandiHaler $^{\circledR}$, or no preference. 


\section{Statistical methods}

The data presented here were prespecified as exploratory endpoints in each of the individual studies. For the purpose of this manuscript, the data were combined post hoc across the 3-month placebo-controlled studies and across the Phase IIIa active comparator studies, and all data were summarized descriptively. The Phase IIIb active comparator study was not integrated with the Phase IIIa studies because of being performed in a different timeframe and having a simplified study design compared with the Phase IIIa studies. No formal statistical analyses were performed. Unless otherwise stated, all summaries used the intent-to-treat population (all randomized patients that took $\geq 1$ dose of study medication).

\section{Results}

\section{Patient demographics}

Patient demographics were similar between the two 3-month placebo-controlled studies; ${ }^{20}$ demographics were also comparable between the two Phase IIIa active comparator studies ${ }^{17}$ and between treatment groups in the Phase IIIb active comparator study. ${ }^{21}$

\section{Treatment compliance}

Treatment compliance for the 3-month placebo-controlled studies and overall treatment compliance across the three active-comparator studies was high, with $\geq 84 \%$ patients being $\geq 95 \%$ (and $\leq 105 \%$ ) compliant with study medication (Tables 1, 2, and S1).

\section{Correct use, ease of use, and remaining dose determination (3-month placebo- controlled studies)}

Following the initial instruction on how to use the Ellipta ${ }^{\mathrm{TM}}$ DPI inhaler in each of the two 3-month placebo-controlled studies, of the 632 patients who took part in the study, 618
(98\%) used the Ellipta ${ }^{\mathrm{TM}}$ DPI correctly at randomization on Day 1 (Table 3). In total (both studies combined), 14 (2\%) patients required additional demonstration; of these, two patients required two additional demonstrations. Only one enrolled patient was excluded at randomization for failure of proper inhaler use (NCT01323660). When inhaler usage was reassessed at 6 weeks, $99 \%$ patients remaining in the study were using their Ellipta ${ }^{\mathrm{TM}}$ DPI correctly (Table 3). After 6 weeks, $99 \%$ of patients reported that they found the inhaler easy or very easy to use and $99 \%$ also reported that they found the dose counter easy or very easy to read (Table 3). Less than $1 \%$ of patients reported that they found the Ellipta ${ }^{\mathrm{TM}}$ DPI difficult to use, and no patients found the Ellipta ${ }^{\mathrm{TM}}$ DPI very difficult to use.

\section{Inhaler preference (active comparator studies)}

In the combined analyses from the two Phase IIIa active comparator studies, patients declared a preference for the Ellipta $^{\mathrm{TM}}$ DPI compared with the HandiHaler ${ }^{\circledR}$ in relation to the number of steps to use ( $59 \%$ vs $17 \%$ ), time taken to use ( $62 \%$ vs $14 \%)$ and ease of use ( $63 \%$ vs $15 \%)$, although $22 \%-24 \%$ of all patients declared no preference for either inhaler (Table 4). Results were similar in the Phase IIIb active comparator study (Table S2). These results were consistent regardless of which inhaler contained active drug in all three active comparator studies (Tables 4 and S2).

\section{Discussion}

This article describes the exploratory outcomes of Ellipta ${ }^{\mathrm{TM}}$ DPI usage, ease of use, and inhaler preference during five large Phase III trials of UMEC/VI in patients with COPD.

In the 3-month placebo-controlled studies, following a simple training regime, the majority ( $98 \%$ ) of patients demonstrated good technique using the Ellipta ${ }^{\mathrm{TM}}$ DPI after one attempt, with only $2 \%$ requiring further demonstration.

Table I Summary of treatment compliance across the two 3-month placebo-controlled studies (I I4II7/II44|8; ITT population)

\begin{tabular}{|c|c|c|c|c|c|c|}
\hline Compliance & $\begin{array}{l}\text { Placebo, } \\
\text { n (\%) N=32I }\end{array}$ & $\begin{array}{l}\text { UMEC } 62.5 \mathrm{mcg} \text {, } \\
\text { n (\%) } \mathrm{N}=89\end{array}$ & $\begin{array}{l}\text { UMEC I } 25 \text { mcg, } \\
\text { n (\%) N=9 I }\end{array}$ & $\begin{array}{l}\text { VI } 25 \text { mcg, } \\
\text { n (\%) N=I40 }\end{array}$ & $\begin{array}{l}\text { UMEC/VI 62.5/25 mcg, } \\
\mathrm{n}(\%) \mathrm{N}=282\end{array}$ & $\begin{array}{l}\text { UMEC/VI I } 25 / 25 \mathrm{mcg} \text {, } \\
\text { n (\%) } N=272\end{array}$ \\
\hline $\mathrm{n}$ & 315 & 89 & 88 & 135 & 275 & 265 \\
\hline$<80$ & $2(<I)$ & $\mathrm{I}(\mathrm{I})$ & $I(I)$ & $\mathrm{I}(<\mathrm{I})$ & $\mathrm{I}(<\mathrm{I})$ & $2(<1)$ \\
\hline$\geq 80$ to $<95$ & $32(10)$ & $9(10)$ & $4(5)$ & $11(8)$ & $25(9)$ & $27(10)$ \\
\hline$\geq 95$ to $\leq 105$ & $268(85)$ & $75(84)$ & $79(90)$ & $115(85)$ & $243(88)$ & $229(86)$ \\
\hline$>105$ to $\leq 120$ & II (3) & $2(2)$ & $3(3)$ & $6(4)$ & $5(2)$ & $6(2)$ \\
\hline$>120$ & $2(<I)$ & $2(2)$ & I (I) & $2(I)$ & $\mathrm{I}(<\mathrm{I})$ & $\mathrm{I}(<\mathrm{I})$ \\
\hline
\end{tabular}

Notes: $\mathrm{N}$ is the number of patients in the ITT population; $\mathrm{n}$ is the number of patients with analyzable data. Compliance data were accessed separately in each treatment period.

Abbreviations: ITT, intent-to-treat; UMEC, umeclidinium bromide; VI, vilanterol. 
Table 2 Summary of treatment compliance across the two 6-month active comparator studies (I I3360// I3374; ITT population)

\begin{tabular}{ll}
\hline Compliance \% & $\begin{array}{l}\text { Overall, } \\
\mathbf{n}(\%) \mathbf{N}=\mathbf{I , 7} \mathbf{~ I 2}\end{array}$ \\
\hline $\mathrm{n}$ & $\mathrm{I}, 678$ \\
$<80$ & $18(\mathrm{I})$ \\
$\geq 80$ to $<95$ & $219(\mathrm{I} 3)$ \\
$\geq 95$ to $\leq 105$ & $1,418(85)$ \\
$>105$ to $\leq 120$ & $15(<\mathrm{I})$ \\
$>120$ & $8(<\mathrm{I})$ \\
\hline
\end{tabular}

Notes: $\mathrm{N}$ is the number of patients in the ITT population; $\mathrm{n}$ is the number of patients with analyzable data.

Abbreviation: ITT, intent-to-treat.

After 6 weeks of use, $99 \%$ of patients were still using the Ellipta $^{\mathrm{TM}}$ DPI correctly.

Provision of a dose counter as a feature of inhaler design can help patients be aware when to seek a new inhaler, an important attribute for maintenance medication. In our studies, the majority $(99 \%)$ of patients found the Ellipta ${ }^{\mathrm{TM}}$

Table 3 Ellipta $^{\mathrm{TM}}$ dry powder inhaler correct use, ease of use, and remaining dose determination (3-month placebo-controlled studies, II44I7/I I44I8; ITT population)

\begin{tabular}{|c|c|c|}
\hline & Response & $\begin{array}{l}\text { Total, n (\%) } \\
\mathrm{N}=655^{\mathrm{a}}\end{array}$ \\
\hline \multicolumn{3}{|l|}{ Day I } \\
\hline \multirow[t]{4}{*}{ Used correctly } & $\mathrm{n}$ & 632 \\
\hline & Yes & $618(98)$ \\
\hline & No & $14(2)$ \\
\hline & Missing & 0 \\
\hline \multicolumn{3}{|l|}{ Day 2} \\
\hline \multirow[t]{4}{*}{ Used correctly } & $\mathrm{n}$ & 629 \\
\hline & Yes & $625(>99)$ \\
\hline & No & $4(<1)$ \\
\hline & Missing & 0 \\
\hline \multicolumn{3}{|l|}{ Week 6} \\
\hline \multirow[t]{4}{*}{ Used correctly } & $\mathrm{n}$ & 587 \\
\hline & Yes & 580 (99) \\
\hline & No & $6(1)$ \\
\hline & Missing & $\mathrm{I}(<\mathrm{I})$ \\
\hline \multirow[t]{5}{*}{ Ease of use rating } & $\mathrm{n}$ & 587 \\
\hline & Very easy & $433(74)$ \\
\hline & Easy & $147(25)$ \\
\hline & Neutral & $6(1)$ \\
\hline & Difficult & $\mathrm{I}(<\mathrm{I})$ \\
\hline Ease of telling how many & $\mathrm{n}$ & 587 \\
\hline \multirow{4}{*}{ doses left } & Very easy & $47 \mid(80)$ \\
\hline & Easy & $111(19)$ \\
\hline & Neutral & $3(<1)$ \\
\hline & Difficult & $2(<1)$ \\
\hline
\end{tabular}

Notes: about 22 patients from Canada were excluded from these analyses, as they were not included in the inhaler preference part of the studies; one patient was randomized but did not receive study treatment or take part in the test. $\mathrm{N}$ is the number of patients in the total population; $n$ is the number of patients with analyzable data at the current time point.

Abbreviation: ITT, intent-to-treat.
Table 4 Inhaler preference outcomes from using the COPD Device Preference Questionnaire in the two Phase IIla active comparator studies (I I3360/I I3374; ITT population)

\begin{tabular}{|c|c|c|c|}
\hline & $\begin{array}{l}\text { Patients } \\
\text { receiving active } \\
\text { Ellipta }^{\mathrm{TM}} \\
\mathrm{N}=\mathbf{I}, \mathbf{2 7 4} *\end{array}$ & $\begin{array}{l}\text { Patients } \\
\text { receiving active } \\
\text { HandiHaler }^{\circledast} \\
\mathbf{N}=\mathbf{4 1 8}\end{array}$ & $\begin{array}{l}\text { All } \\
\text { patients } \\
N=1,692\end{array}$ \\
\hline \multicolumn{4}{|c|}{ Number of steps, n (\%) } \\
\hline $\mathrm{n}$ & $\mathrm{I}, 228$ & 404 & $\mathrm{I}, 632$ \\
\hline Ellipta $^{\mathrm{TM}}$ & $714(58)$ & $255(63)$ & 969 (59) \\
\hline HandiHaler ${ }^{\circledR}$ & $211(17)$ & $65(16)$ & $276(17)$ \\
\hline No preference & $303(25)$ & $84(21)$ & $387(24)$ \\
\hline \multicolumn{4}{|c|}{ Time needed to use, $n(\%)$} \\
\hline $\mathrm{n}$ & $\mathrm{I}, 228$ & 404 & 1,632 \\
\hline Ellipta $^{\mathrm{TM}}$ & $749(61)$ & $268(66)$ & $1,017(62$ \\
\hline HandiHaler ${ }^{\circledR}$ & $181(15)$ & 44 (II) & $225(14)$ \\
\hline No preference & $298(24)$ & $92(23)$ & $390(24)$ \\
\hline \multicolumn{4}{|c|}{ Ease of use, n (\%) } \\
\hline $\mathrm{n}$ & $\mathrm{I}, 228$ & 404 & $\mathrm{I}, 632$ \\
\hline Ellipta $^{\mathrm{TM}}$ & $760(62)$ & $260(64)$ & I,020 (63 \\
\hline HandiHaler ${ }^{\circledR}$ & $199(16)$ & $52(13)$ & $25 \mid(I 5)$ \\
\hline No preference & $269(22)$ & $92(23)$ & $36 I(22)$ \\
\hline
\end{tabular}

Notes: $\mathrm{N}$ is the number of patients in the total population; $\mathrm{n}$ is the number of patients with analyzable data at the current time point. *This group includes patients receiving UMEC/VI, UMEC, or VI.

Abbreviations: COPD, chronic obstructive pulmonary disease; ITT, intentto-treat; UMEC/VI, umeclidinium/vilanterol; UMEC, umeclidinium; VI, vilanterol.

DPI dose counter to be easy/very easy to read. Our results concur with a previous qualitative study conducted in patients with asthma and COPD, in which patients $(\mathrm{n}=75)$ reported high levels of satisfaction with the Ellipta ${ }^{\mathrm{TM}}$ DPI, describing it as straightforward to operate and easy to use. ${ }^{19}$ When interviewed, patients favored the size and mouthpiece fit over other inhalers. ${ }^{19}$ Dose counter visibility, simplicity of operation, and ease of use were also apparent drivers for patient preference over Diskus ${ }^{\circledR}$, HandiHaler ${ }^{\circledR}$, and various metered dose inhalers. ${ }^{19}$

In the three active comparator studies, patients expressed preference for the Ellipta ${ }^{\mathrm{TM}}$ DPI over the HandiHaler ${ }^{\circledR}$ regardless of whether the preferred inhaler contained active drug or placebo. These findings suggest independence from the efficacy outcomes reported in these studies, as the administration of placebo or three different active bronchodilator therapies via the Ellipta ${ }^{\mathrm{TM}}$ DPI did not impact the preference for this inhaler versus the HandiHaler ${ }^{\circledR}$.

Several other factors are known to influence treatment compliance in COPD, for example, suboptimal inhaler technique can result in poor disease control. ${ }^{4,23,24}$ Furthermore, if an inhaler is simple to use, patients are more likely to adhere to treatment regimens. ${ }^{2}$ Nonintentional noncompliance, that is, if a patient unknowingly makes mistakes during treatment administration, can be minimized by using easy-to-use 
inhalers and a less complex, easy-to-follow treatment regimen. ${ }^{2,24,25}$ The ability to provide single (UMEC) and dual therapies (FF/VI and UMEC/VI) using the ElliptaTM DPI supports this simplification. Intentional noncompliance with therapy, where a patient chooses to abstain from taking treatment, is less easily addressed by inhaler design alone although characteristics, such as shape, dimension, and cost may impact patient attitudes in taking treatment. ${ }^{2,25}$

Patients with COPD are a medically diverse group with variations in lung function, lifestyle, comorbidities, and intellectual ability impacting treatment choice and adherence. ${ }^{26}$ Patients with COPD tend to be older than their asthma counterparts and therefore more likely to have physical and cognitive impairments that may affect their ability to use an inhaler. Furthermore, these patients are more likely to have comorbid conditions and, therefore, take multiple medications, ${ }^{4,24,26}$ further highlighting the need for a simple treatment regimen with minimal number of inhalers. Other key factors relating to inhaler "misuse" include level of education and quality of instruction. ${ }^{23,24}$ Patient training often needs to be repeated in order to maintain correct inhaler technique. ${ }^{3}$ The results from the five assessed Phase III studies indicated that it was easy to learn and maintain the correct technique to deliver UMEC/ VI using the ElliptaTM DPI. Although these studies included correct use of inhaler assessments and patient questionnaires, no direct measurement of inhaler technique was performed.

Patient satisfaction with and preference for a specific inhaler can also impact adherence to therapy and conse-

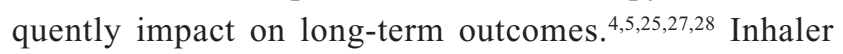
preference is now a recognized and valid patient-reported outcome for inclusion in clinical trials involving aerosolized medicines where a double-dummy design is used. ${ }^{25,27,28}$ However, a general lack of precision in measuring inhaler preference has been reported. ${ }^{28}$ Instruments, such as nonvalidated questionnaires and response scales, and questionnaires developed without input from relevant patients or psychometric testing have been commonly used, ${ }^{28}$ which may lead to increased variability in results. Validated questionnaires are now being developed, although the Patient Satisfaction and Preference Questionnaire is currently the only one with published validation. ${ }^{28}$ Measures of patient preference can only be obtained where study design provides patients' experience of the use of both inhalers requiring a double-dummy or crossover design. In these studies, the attributes of each inhaler to be compared need to be taken into account. Attributes that may be affected by any blinding process were not compared, to make the findings as generalizable as possible to routine clinical practice.
Participant feedback on the recently developed CDPQ used in three of our studies suggests that the questionnaire items represent the most important concepts in determining COPD inhaler preference relating to ease of use concepts from the patient perspective. ${ }^{22}$

Furthermore, confirmation was obtained during its development that the final wording of the instructions, the items, and their responses were well understood by the patients with COPD, thus providing evidence that the questionnaire adequately and appropriately assessed DPI preference in patients with COPD relating to ease of use. ${ }^{22}$ These results were consistent across the three active comparator studies and show a preference for the Ellipta ${ }^{\mathrm{TM}}$ DPI over the HandiHaler $^{\circledR}$. The Ellipta ${ }^{\mathrm{TM}}$ DPI was not available in clinical practice at the time of the trials; hence, there was a possibility that patient familiarity with the HandiHaler ${ }^{\circledR}$ may have biased patient preference in favor of the HandiHaler ${ }^{\circledR}$, although this was not assessed in these Phase III studies. Furthermore, the Ellipta $^{\mathrm{TM}}$ DPI enables multiple dosage and does not require dose preparation, two factors known to have the greatest influence on patient preference. ${ }^{25}$

Treatment compliance was high in all five studies, and this is to be expected under the controlled environment of a clinical trial. However, compliance was assessed by dose counter or dose counting and no electronic registration of dosing was performed in these studies, which could be a limitation, and the usability of the Ellipta ${ }^{\mathrm{TM}}$ DPI should also be tested in the real-life setting of clinical practice.

\section{Conclusion}

The majority of patients with COPD in these Phase III studies found the Ellipta ${ }^{\mathrm{TM}}$ DPI easy to use. In addition, the majority of patients expressed a preference for the Ellipta ${ }^{\mathrm{TM}}$ DPI over the HandiHaler ${ }^{\circledR}$, potentially improving patient compliance and outcomes. Further assessment is warranted to determine whether this holds true in the clinical setting.

\section{Acknowledgments}

Medical writing and editorial support was provided by Dr Kathryn White of Cathean Ltd and David Griffiths $\mathrm{PhD}$ and Joanne Ashworth of Fishawack Indicia Ltd. All medical writing and editorial support was funded by GlaxoSmithKline. Development of the CDPQ, these clinical studies, and analyses were funded by GlaxoSmithKline.

\section{Author contribution}

JHR, MT, NR, AD, AC, and SSH participated in the concept and design of the study. All the authors participated in the 
design of the analysis plan and the interpretation of the data. $\mathrm{AD}$ analyzed the data. All the authors critically revised the manuscript and approved the final manuscript. MT and AC participated in the development of the CDPQ.

\section{Disclosure}

All authors were employees of GSK at the time of the study and hold stocks and shares in the company. NR is now at Worldwide Clinical Trials, Morrisville, NC, USA (NR was previously employed by GSK and holds stocks/shares in GSK). The authors report no other conflicts of interest in this work.

\section{References}

1. Mannino DM, Buist AS. Global burden of COPD: risk factors, prevalence, and future trends. Lancet. 2007;370(9589):765-773.

2. Price D, Bosnic-Anticevich S, Briggs A, et al. Inhaler competence in asthma: common errors, barriers to use and recommended solutions. Respir Med. 2013;107(1):37-46.

3. Hammerlein A, Muller U, Schulz M. Pharmacist-led intervention study to improve inhalation technique in asthma and COPD patients. $J$ Eval Clin Pract. 2011;17(1):61-70.

4. Restrepo RD, Alvarez MT, Wittnebel LD, et al. Medication adherence issues in patients treated for COPD. Int J Chron Obstruct Pulmon Dis. 2008;3(3):371-384.

5. Brocklebank D, Ram F, Wright J, et al. Comparison of the effectiveness of inhaler devices in asthma and chronic obstructive airways disease: a systematic review of the literature. Health Technol Assess. 2001;5(26):1-149.

6. Hansel TT, Barnes PJ. New drugs and targets for asthma and COPD. In: Bolliger CT, editor. Progress in Respiratory Research. London: Karger; 2010.

7. Taki M, Marriott C, Zeng XM, Martin GP. The aerodynamic deposition of drugs from combination DPI formulations: the influence of particle size and drug-drug interactions. $J$ Aerosol Med Pulm Drug Deliv. 2009;22:285-306.

8. Grant AC, Walker R, Hamilton M, Garrill K. The ELLIPTA ${ }^{\circledR}$ dry powder inhaler: design, functionality, in vitro dosing performance and critical task compliance by patients and caregivers. J Aerosol Med Pulm Drug Deliv. 2015;28(6):474-485.

9. Woodcock A, Lotvall J, Busse WW, et al. Efficacy and safety of fluticasone furoate 100 mug and 200 mug once daily in the treatment of moderate-severe asthma in adults and adolescents: a 24-week randomised study. BMC Pulm Med. 2014;14:113.

10. Kerwin EM, Scott-Wilson C, Sanford L, et al. A randomised trial of fluticasone furoate/vilanterol (50/25 mug; 100/25 mug) on lung function in COPD. Respir Med. 2013;107(4):560-569.

11. Martinez FJ, Boscia J, Feldman G, et al. Fluticasone furoate/vilanterol (100/25; 200/25 mug) improves lung function in COPD: a randomised trial. Respir Med. 2013;107(4):550-559.

12. Calverley PMA, Dransfield MT, Bourbeau J. Safety of fluticasone fuorate (FF), an inhaled corticosteroid in combination with vilanterol (VI), a long-acting beta agonist in management of COPD exacerbations. Eur Respir J. 2012;40(Suppl 56):2113.
13. Dransfield MT, Bourbeau J, Jones PW, et al. Once-daily inhaled fluticasone furoate and vilanterol versus vilanterol only for prevention of exacerbations of COPD: two replicate double-blind, parallel-group, randomised controlled trials. Lancet Respir Med. 2013;1(3):210-223.

14. Donohue JF, Kalberg C, Shah P, et al. Dose response of umeclidinium administered once or twice daily in patients with COPD: a pooled analysis of two randomized, double-blind, placebo-controlled studies. J Clin Pharmacol. 2014;54(11):1214-1220.

15. Donohue JF, Maleki-Yazdi MR, Kilbride S, Mehta R, Kalberg C, Church A. Efficacy and safety of once-daily umeclidinium/vilanterol 62.5/25 mcg in COPD. Respir Med. 2013;107(10):1538-1546.

16. Donohue JF, Niewoehner D, Brooks J, O’Dell D, Church A. Safety and tolerability of once-daily umeclidinium/vilanterol $125 / 25 \mathrm{mcg}$ and umeclidinium $125 \mathrm{mcg}$ in patients with chronic obstructive pulmonary disease: results from a 52-week, randomized, double-blind, placebocontrolled study. Respir Res. 2014;15:78.

17. Decramer M, Anzueto A, Kerwin E, et al. Efficacy and safety of umeclidinium plus vilanterol versus tiotropium, vilanterol, or umeclidinium monotherapies over 24 weeks in patients with chronic obstructive pulmonary disease: results from two multicentre, blinded, randomised controlled trials. Lancet Respir Med. 2014;2(6):472-486.

18. Trivedi R, Richard N, Mehta R, Church A. Umeclidinium in patients with COPD: a randomised, placebo-controlled study. Eur Respir J. 2014;43(1):72-81.

19. Svedsater H, Dale P, Garrill K, Walker R, Woepse MW. Qualitative assessment of attributes and ease of use of the ELLIPTA dry powder inhaler for delivery of maintenance therapy for asthma and COPD. BMC Pulm Med. 2013;13:72.

20. Maltais F, Singh S, Donald AC, et al. Effects of a combination of umeclidinium/vilanterol on exercise endurance in patients with chronic obstructive pulmonary disease: two randomized, double-blind clinical trials. Ther Adv Respir Dis. 2014;8(6):169-181.

21. Maleki-Yazdi MR, Kaelin T, Richard N, Zvarich M, Church A. Efficacy and safety of umeclidinium/vilanterol $62.5 / 25 \mathrm{mcg}$ and tiotropium $18 \mathrm{mcg}$ in chronic obstructive pulmonary disease: results of a 24-week, randomized, controlled trial. Respir Med. 2014;108(12):1752-1760.

22. Clark M, Hofmann A, Tabberer M, Martin S. Development and content validity of the COPD device preference questionnaire. Value Health. 2011;14(7):PA255.

23. Melani AS, Bonavia M, Cilenti V, et al. Inhaler mishandling remains common in real life and is associated with reduced disease control. Respir Med. 2011;105(6):930-938.

24. Lareau SC, Yawn BP. Improving adherence with inhaler therapy in COPD. Int J Chron Obstruct Pulmon Dis. 2010;5:401-406.

25. Lavorini F, Fontana GA. Inhaler technique and patient's preference for dry powder inhaler devices. Expert Opin Drug Deliv. 2014; 11(1): $1-3$.

26. Fromer L, Goodwin E, Walsh J. Customizing inhaled therapy to meet the needs of COPD patients. Postgrad Med. 2010;122(2):83-93.

27. Anderson P. Patient preference for and satisfaction with inhaler devices. Eur Respir Rev. 2005;14(96):109-116.

28. Hodder R, Price D. Patient preferences for inhaler devices in chronic obstructive pulmonary disease: experience with Respimat Soft Mist inhaler. Int J Chron Obstruct Pulmon Dis. 2009;4:381-390. 


\section{Supplementary materials Methods}

Active comparator studies

In the three active comparator studies, a double-dummy design (described previously ${ }^{1,2}$ ) was used for dosing, whereby patients were given two inhalers, one containing active drug and the other placebo. All the patients and physicians were masked to assigned treatment during these studies; however, the tiotropium (TIO) capsules had trade markings that were not present on the placebo capsules, although they were closely matched in color. ${ }^{1,2}$ Both the TIO and placebo blister packages were covered with opaque overlabels in order to hide the information on the TIO packaging. The HandiHaler ${ }^{\circledR}$ dry powder inhalers were also covered with labels to mask the identifying marks on the inhaler.

As the Phase IIIa studies were of parallel-group design, the capsule type was consistent for each patient for the duration of each of these studies. ${ }^{1}$

\section{COPD Device Preference Questionnaire development}

The final version of the COPD Device Preference Questionnaire (CPDQ) is shown below:

INSTRUCTIONS: Please complete the following questions related to both the Novel dry powder inhaler and Handihaler devices that you used during this study. Check only one response for each question.

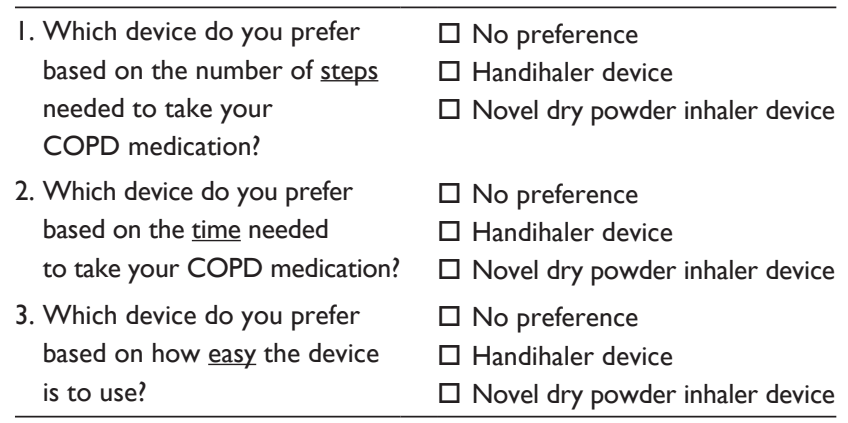

International Journal of COPD

\section{Publish your work in this journal}

The International Journal of COPD is an international, peer-reviewed journal of therapeutics and pharmacology focusing on concise rapid reporting of clinical studies and reviews in COPD. Special focus is given to the pathophysiological processes underlying the disease, intervention programs, patient focused education, and self management protocols.
Table SI Summary of treatment compliance in the Phase IIlb active comparator study (II7II5; ITT population)

\begin{tabular}{ll}
\hline Compliance & $\begin{array}{l}\text { Total } \\
\mathbf{N}=\mathbf{9 0 5}\end{array}$ \\
$\mathrm{n}$ & 883 \\
Compliance category, $\mathbf{n}(\%)$ & \\
$<80$ & $8(<1 \%)$ \\
$\geq 80$ to $<95$ & $45(5 \%)$ \\
$\geq 95$ to $\leq 105$ & $827(94 \%)$ \\
$>105$ to $\leq 120$ & $2(<1 \%)$ \\
$>120$ & $1(<1 \%)$ \\
\hline
\end{tabular}

Notes: $\mathrm{N}$ is the number of patients in the ITT population; $\mathrm{n}$ is the number of patients with analyzable data.

Abbreviation: ITT, intent-to-treat.

Table S2 Inhaler preference outcomes from using the COPD Device Preference Questionnaire in the Phase Illb active comparator study (intent-to-treat population)

\begin{tabular}{|c|c|c|}
\hline & $\begin{array}{l}\text { Patients } \\
\text { receiving active } \\
\text { Ellipta }^{\mathrm{TM}} \\
\mathbf{N}=\mathbf{4 5 4}\end{array}$ & $\begin{array}{l}\text { Patients } \\
\text { receiving active } \\
\text { HandiHaler }^{\circledR} \\
\mathrm{N}=\mathbf{4 5} \text { I }\end{array}$ \\
\hline \multicolumn{3}{|c|}{ Number of steps, n (\%) } \\
\hline $\mathrm{n}$ & 441 & 434 \\
\hline Ellipta TM $^{\mathrm{T}}$ & 262 (59) & $242(56)$ \\
\hline HandiHaler ${ }^{\circledR}$ & $68(15)$ & $68(16)$ \\
\hline No preference & III (25) & $124(29)$ \\
\hline \multicolumn{3}{|c|}{ Time needed to use, $\mathbf{n}(\%)$} \\
\hline $\mathrm{n}$ & 441 & 434 \\
\hline Ellipta $^{\mathrm{TM}}$ & $270(6 I)$ & $256(59)$ \\
\hline HandiHaler $^{\circledR}$ & $65(15)$ & $59(14)$ \\
\hline No preference & $106(24)$ & $119(27)$ \\
\hline \multicolumn{3}{|c|}{ Ease of use, $n(\%)$} \\
\hline $\mathrm{n}$ & $44 I$ & 434 \\
\hline Ellipta TM & $283(64)$ & $256(59)$ \\
\hline HandiHaler ${ }^{\circledR}$ & $61(14)$ & $62(14)$ \\
\hline No preference & $97(22)$ & $116(27)$ \\
\hline
\end{tabular}

Notes: $\mathrm{N}$ is the number of patients in the ITT population; $\mathrm{n}$ is the number of patients with analyzable data.

Abbreviations: COPD, chronic obstructive pulmonary disease; ITT, intent-to-treat.

\section{References}

1. Decramer M, Anzueto A, Kerwin E, et al. Efficacy and safety of umeclidinium plus vilanterol versus tiotropium, vilanterol, or umeclidinium monotherapies over 24 weeks in patients with chronic obstructive pulmonary disease: results from two multicentre, blinded, randomised controlled trials. Lancet Respir Med. 2014;2(6):472-486.

2. Maleki-Yazdi MR, Kaelin T, Richard N, Zvarich M, Church A. Efficacy and safety of umeclidinium/vilanterol $62.5 / 25 \mathrm{mcg}$ and tiotropium $18 \mathrm{mcg}$ in chronic obstructive pulmonary disease: results of a 24-week, randomized, controlled trial. Respir Med. 2014;108(12):1752-1760.

\section{Dovepress}

This journal is indexed on PubMed Central, MedLine and CAS. The manuscript management system is completely online and includes a very quick and fair peer-review system, which is all easy to use. Visit http://www.dovepress.com/testimonials.php to read real quotes from published authors. 